\title{
MECHANISMS FOR RADIATION DAMAGE IN DNA
}

\author{
Progress Report
}

Michael D. Sevilla

0akland University

Rochester, Michigan

June 1, 1973 - May 31, 1974

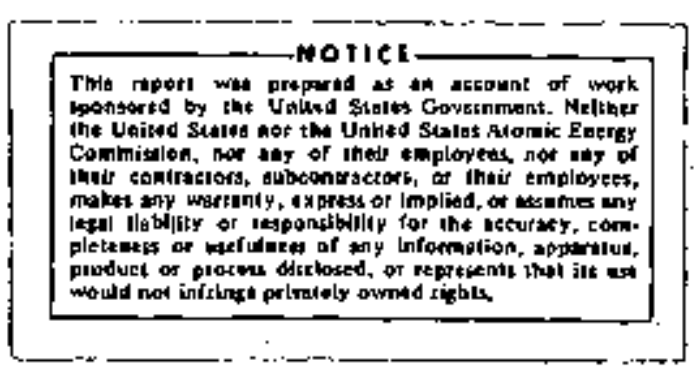

Prepared for the Division of Biomedical and Environmental Research

of the U.S. Atomic Energy Commission under Contract No. AT(11-1)-2364

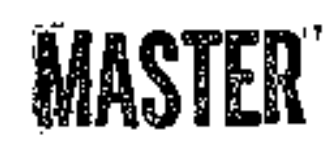




\section{DISCLAIMER}

This report was prepared as an account of work sponsored by an agency of the United States Government. Neither the United States Government nor any agency Thereot, nor any of their employees, makes any warranty, express or implied, or assumes any legal liability or responsibility for the accuracy, completeness, or usefulness of any information, apparatus, product, or process disclosed, or represents that its use would not infringe privately owned rights. Reference herein to any specific commercial product, process, or service by trade name, trademark, manufacturer, or otherwise does not necessarily constitute or imply its endorsement, recommendation, or favoring by the United States Government or any agency thereof. The views and opinions of authors expressed herein do not necessarlly state or reflect those of the United States Government or any agency thereof. 


\section{DISCLAIMER}

Portions of this document may be illegible in electronic image products. Images are produced from the best available original document. 
Abstract $\ldots \ldots \ldots \ldots \ldots \ldots \ldots \ldots \ldots \ldots \ldots \ldots \ldots \ldots \ldots \ldots \ldots \ldots \ldots$

I. Introduction $\ldots \ldots \ldots \ldots \ldots \ldots \ldots \ldots \ldots \ldots \ldots \ldots \ldots \ldots, 2$

II. Results to Date $\ldots \ldots \ldots \ldots \ldots \ldots \ldots \ldots \ldots \ldots \ldots \ldots \ldots \ldots \ldots$

A. Negative Ions of the DNA Bases.............. 3

B. Positive Ions of the DNA Bases..............4

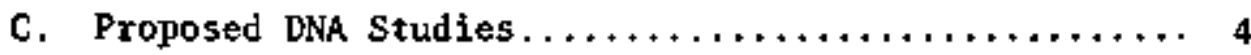

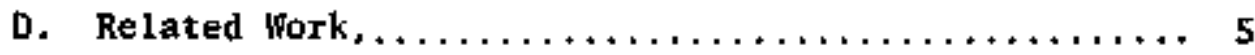

1. Reactions of Electrons with

s-Halouracils $\ldots \ldots \ldots \ldots \ldots \ldots \ldots \ldots \ldots \ldots \ldots$ s

2. Reactions of Electrons with

Amino Acids and Peptides.............. 5

Appendix A. An ESR Study of Pyrimidine, Pyrimidine Nucleoside and Halopyrimidine Anions

Appendix B. An ESR Study of Several DNA Base Cation Radicals Produced by Photoionization

Appendix c. Reactions of The Catton and Anion Radicals of Several DNA Bases 


\section{Abstract}

In this project we have proposed a mechanism for radiation damage to DNA and detailed a series of experiments utilizing electron spin resonance spectrometry to test the proposed mechanism. Thus far we have produced and investigated the positive and negative ions of a number of purine and pyrimidine DNA bases in aqueous glasses. The $g$ values and hyperfine couplings, both anisotroptc and isotropic, have been determined when possible. It has been found that 5 -methyl substituted pyrimidine cations (thymine, thymidine, 5-methyicytosine and 5-methylcytidine) react in these aqueous systems by deprotonation of the 5-methyl group. The thymine anion has been found to protonate in neutral aqueous glasses. Investigations of the cation and anion radicals of the other DNA bases have showr a lessened tendency toward further reaction. In related work we have studied the reactions of electrons with 5-halouracils as well as anino acids and peptides. In our work with 5-halouracils we have isolated the anions found their relative stability and followed their. further reactions. Our results were found to be in agreement with those of other experimental methods. 


\section{Introduction}

This project proposes a mechanism for radiation danage to DNA and suggests a series of experiments to test the proposed mechanism.

Briefly described the mechanism is that positive and negative ions formed with the DNA strand migrate through the stacked DNA bases and subsequently react with the DNA base most 1 ikely to react towards protonation of the anion and decomposition of the cation. It is suggested that the thymine anion and thymine cation are the DNA base ions which most probably will react in this manner. Thus ions formed within the DNA strand would localize the radiation damage predoninantly on the thymine base.

- In our previous proposal we suggested mork along three lines to test the proposed mechanism for radiation damage to DNA. First the anions of the DNA bases would be produced and theit further reactions studied. Second the positive ions of the DNA bases were to be produced and their further reactions investigated. Finally experiments on $\gamma$-irradiated DNA were to be performed. 
II. Resuits to Date

We have made good progress on the studies of the positive and negative ions of the DNA bases. These results are described briefly belaw and in more detail in our publications and preprints which are included. It should be noted that some of the work described was performed during the period between the approval of the proposal (September, 1971) and its funding (June, 1973). This work was generously supported by Oakland University.

A. Negative lons of the DNA Bases.

In an initial report (Appendix A) we produced the anions of a variety of pyrimidine DNA bases. We showed in this work that the 6 position carbon which is known to be the site of protonation in the thymine anion is also the site of high unpaired spin density. We later studied the protonation reactions of thymine anion and other pyrinidines (Appendix C). We found that thymine protonates most readily among the pyrimidines. In work performed during the past year we have studied the purine anion radicais for possible protonation reactions and to determine their $g$ values for possible identification of these species in single crystals. (Appendix F). We are present1y investigating these possible reactions in nucleoside and nucleotide anions in both neutral (12M LiC1) and alkaline $\left(5 \mathrm{M} \mathrm{K}_{2} \mathrm{CO}_{3}\right)$ glasses. 
B. Positive Ions of the DNA Bases

We have thus far investigated the positive ions of thymine, thymidine, 5-methylcytosine, and 5-methylcytidine

(Appendices B, C). We have found that the principal reaction for these 5-methyl substituted pyrimidines is deprotonation of the metlyy group.

In the past year we have produced the positive ions of the purine DNA bases and found their $g$ values for possible identification of these species in single crystals (Appendix F) .

At present we are investigating the positive ions of purine and pyrimidine nucleosides and nucleotides to determine whether possible deprotonation reactions occur at the ribose group (see proposal page 18). This would be a posstble reaction mechanism in DNA radiolysis and is therefore of interest.

C. Proposed DHA Studies

We have not yet begun our investigations of $\gamma$-irradiated DNA. Since we plan to perform experiments on DNA in conjunction with our studies of the DNA subunits, we will perform experinents this next year as outlined in the proposal. It is of course most important to the final analysis of the ESR spectrum of $\gamma$-irradiated DNA that the reactions of the individual subunits be known. Since it is our thesis that most of the damage in DNA should at some intermediate state be localized on thymine and since we 
5.

investigated the likely reactions of the thymine ion

precursors, we believe these preliminary investigations of

DNA are justified at this time.

D. Related Nork

1. Reactions of Electrons with 5-Halouracils

The proposed mechanism for radiation danage to DNA is applicable to 5-bromouracil containing DNA as well. It is well known that 5-bromouracil undergoes reductive debromination to forn a uracilyl radical. In DNA it has been proposed that the uracilyl radical formed abstracts from a rebose group and this ultimately results in strand breakage (J. E. Zimbrick, J, F. Ward and L. S. Myers, Jr. Int. J. Radiat, Biol., 16, 505 (1969). We would simply add that electron addition to bromouracil comes by migration of the electron through the stacked DNA bases in the DHA strand. In our work on 5-halouracils we have been the first in ESR experiments to isolate the anions of the S-halouracils and follow their reactions (Appendix E). Our results were found to be in agreement with other techniques, of special interest was the observation that the uracilyl radical was found to hydrate to form a sonewhat more stable radical species. This is suggested as a possible competing mechanism with abstraction in DKA. 2. Reactions of Electrons with Amino Acids and Peptides Our work on electron reactions with amino acids and peptides is the latest in a series of papers dealing with 
this subject. (Appendix D), In this work we have stadied the influence of $\mathrm{pH}$ on subsequent reactions after electron attachment. We found that the relative stabilities of the various radicals produced after electron at tachment were changed; however, new radical species were in general not produced due to the change in pH. Although this work is not dircetly related with the proposed work, eventually such work should have significance to the radiolysis of DNA on chromosomes. In such systems DNA is surrounded by protein (histones) and can be attacked by radicals generated in the histones. 


\title{
RADICALS FORMED AFTER ELECTRON ATTACMMENT TO
}

5-HALOURACILS IN AQUEOUS CLASSES

\author{
M. D. Sevilla, R. Failor and G. Zorman \\ Department of Chemistry \\ Ookland University \\ Rochester, Michigan 48063
}

ACCEPTED FOR PUBLICATION IN THE JOURNAL OF PHYSICAL CHEMISTRY 


\section{Abstroset}

Radicals produced after electron attachment to 5-bromo-6-methylurac: and the 5-halouracils at $77^{\circ} \mathrm{K}$ in neutral (I2M LiCl) and alkaline (BM NaOH) aqueous glasses have been investigated by ESR spectroscopy. Electron attachment to 5-bromo-6-methyluracil in $12 \mathrm{M} \mathrm{LiCl}$ a $77^{\circ} \mathrm{K}$ results in an anion radical. The anion dehalogenates upon warming to $150^{\circ} \mathrm{K}$ to form the 6-methyluracil-5-yl radical. Esr spectra indicate that upon further warming this second species undergoes hydrolysis to form the 5-hydroxy-6-methyl-(5,6)-dihydrouracil-6-yl radical. The results for the holouracils in I2M LiCl suggest stable anions for bromo-, chloroand fluorouracil at $77^{\circ} \mathrm{K}$. Warming the bromouracil anion to $155^{\circ} \mathrm{K}$ results in a spectrum attrilbuted to the uracilyl radical. The chloroand fluorouracll anions are stable at this temperature. Warming to $165^{\circ} \mathrm{K}$ results in the hydrolysis of the uracilyl radical to form a radical analogous to that found for 5-bromo-6-methyluracit, Some nydrolysis is noted for chlorouracil indicating partial dehalogenation of the anion. The fluorouracil anion remained stabte at this temperature. In $8 \mathrm{M}$ NaOD the $\pi$-anions were found to be somewhat less stable. The 7-anions of 5-bromouracil and 5-bromo-6-methyluracil were not observed at $77 \mathrm{~K}$; however, those of chloro and fluorourac is were observed. The difference, in stability of the anions in the two glasses is attributed to the fact that the nitrogens are protonated in the neutral glass wheress they are not in the alkal ine giass. In addition protonation of the anion at an oxygen in the neutral glass is also 5 ikely. This would produce a neutral radical and further stabljze the radical. 


\section{Introduction}

The radiation sensistivity of 5-bromouracil containing DNA has produced considerable interest in the radiation chemistry of 5-halouracils. 2 This sensitivity has been attributed to the dehalogenation of bromine after attack by radiolytic internedlates. 2 A number of studtes employing differing techniques have shows that one of these radiolytic intermediates, the electron, induces reductive dehalogenation in 5-halouracils. 3 the primary intermedtates, the anion radicals, have been observed in pulse radiolytic experiments in the cases of fluorom and ehlorouracit. 4 The bromouracil anion has not been observed in pulse radialytic experiments.

Several esr studies have been performed on the halouracils. In an esr investigation employing steady stafe radiolysis to generate electrons In aqueous solution it was found that the 1 ifetimes of the halouracil anions were too short to be observed. 5 Esr studtes on $\boldsymbol{\gamma}$-irradiated single crystals of 5 malouracils have given evidence for radjcals which could be interpreted as protonated anions; however no evidence for dehalogenation was found. 6,7

Esr studies in alkaline aqueous glasses at low temperature have resulted in reports that the anion radicals of the 5-halouracils are stable at $77^{\mathrm{M}} \mathrm{K}$ and that they are unstable toward dehalogenation at this temperature. 9 In order to resolve this apparent discrepancy as well as to further elucidate the mechanisms of reaction after electron attachment to 5-halouracils, we have investigated the reaction of electrons With these compounds in neutrat and alkal ine aqueous glasses. 


\section{Experimental Section}

5-falouracils mere obtained from Calbiochem (A grade) and used without further purification. 5-Bromo-6-methyluracil was synthesized from 6-methyluracil by the method of Sasaki and Ando. 10 The prodiat was recrystallized from ethanol.

The experimental procedure was essentially thot used in our previous work in $8 \mathrm{M} \mathrm{NaOO}$ and $12 \mathrm{M} \mathrm{LiCl} .9,11,12$ In this technique a solution of I2M LiCJ $/ \mathrm{H}_{2} \mathrm{O}, 12 \mathrm{M} \mathrm{LiCl} / \mathrm{O}_{2} \mathrm{O}(98 \% \mathrm{D})$ or $8 \mathrm{M} \mathrm{HaOO} \mathrm{(Ca,} \mathrm{92 \%} \mathrm{D)} \mathrm{containing}$

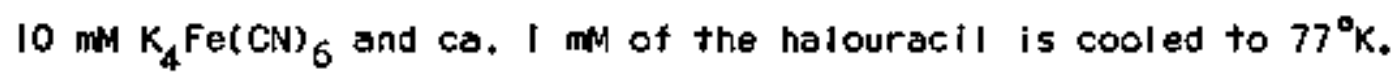
The glass formed is photolized with $254 \mathrm{~nm}$ light at $77^{\circ} \mathrm{K}$ for times usually less than one minute. Trapped electrons formed in the photolysjs are photobleached with filtered light from an incandescent lamp. The filter used ta mixed solution of $\mathrm{K}_{4} \mathrm{Fe}(\mathrm{CN})_{6}$ and $\mathrm{K}_{3} \mathrm{Fe}(\mathrm{CN})_{6}$ ) filtered uv and blue light. This was necessary as several of the anion radicals formed dehalogenated when exposed to untiltered light.

The $g$ values and hyperfine splittings in this work are measured relative to potassium peroxylamine disulfonate $\left\langle A_{N}=13.0 \mathrm{G}\right.$ and $g=$ 2.0056). The $g$ values are measured from the center of the spectrum and are reproducible to to.0003. 


\section{Results and Discussion}

\section{5-6romo-6-Methyluracil}

5-Bromo-6-methyluracil in a neutral alass: 5-Bromo-6-nethyluracil (BrMeU) was investigated to aid our interpretation of the results found for the halouracils which fallow. The substitution of a methyl group st position six allows for a clear distinction between the varlous radicals formed after electron atttachment.

The reaction of electrons with BrMeU in $12 \mathrm{M} \mathrm{LiCl} / \mathrm{D}_{2} \mathrm{O}$ of $77^{\circ} \mathrm{K}$ resulted in the spectrum in Figure IA. Analysis of the ca. 1:3:3:1 quartet vîtds a $16.8 \mathrm{G}$ methyl group splitting with $g=2.0026$. Thts initial spectrum could be due to the anion radical or the 6-methyluracti-5-yl radical (radical II) produced by debromination of the anion. The following evidence strongly supports the anion as the initfal species. First, the methyl group splitting is nearly identical to that found for the methyl group in the 6-methyluracil anion? Next resolution of the methyl proton splittings would not be expected for the 6-methyluracil-5-yl radlcal due to the nature of the interaction in ouradicals. Flnally the observed splitting is in agreement with $\pi$-electron spin density calculations Which indicate a large spin density $\left\{\rho^{\wedge} 0.5\right)$ at position 6 in all uracil and halouracil anions. $8,13,14$ warming the anion to $140^{\circ} \mathrm{K}$ or irradiating With unfiltered I ight from an incandescent I mmp gave the 246 singlet shown in Figure IB. This spectrum is attributed to radical Il produced by debromination as shown in reaction 1. Resolutian of the methyl proton splittings Is not fow d for this radical as expected. 

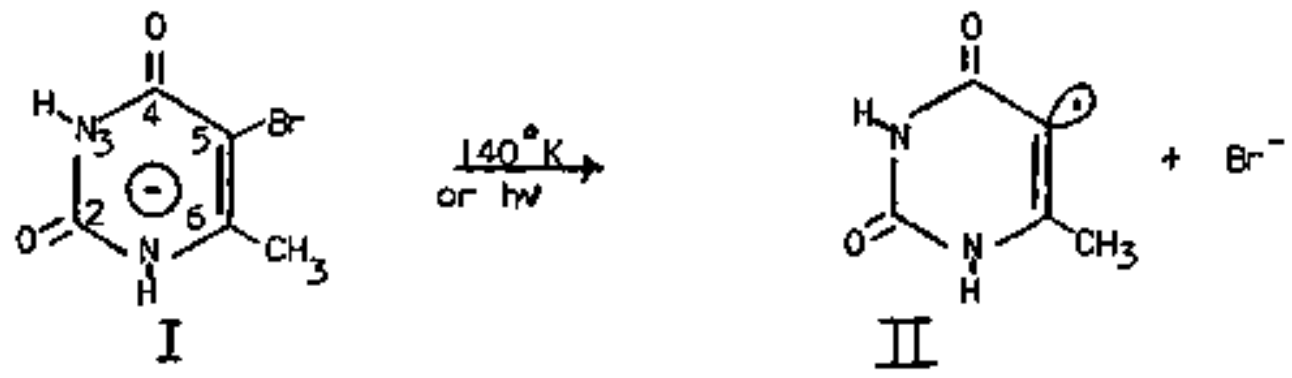

Further warming of radical 프 in LiCl/ $\mathrm{H}_{2} \mathrm{O}$ to $160^{\circ} \mathrm{K}$ resulted in the spectrum shown in Figure IC. The spectrum consists of 6 I ines in the approxImate ratio of intensities $1: 3: 4: 4: 3: 1$. Interpretation of the spectrum yields a $19.5 \mathrm{G}$ splitting due to three equivalent protons and a 42 G splitting due to a single proton. The only radical consistent with such splittings is a radical with one $\theta$-proton at the 5-position and a radical site at position 6 . This strongly suggests that the hydration reaction (reaction 2) takes place on warming to form the 5-hydroxy-6-methyl$(5,6)$-dihydrouracil-6-yl radical (ID).<smiles></smiles><smiles>CC1=C(C)C(O)C(=O)NC1=O</smiles>

This is confirmed by the tact that a quartet of $20 \mathrm{G}$ is observed in $\mathrm{LiCl} / \mathrm{O}_{2} \mathrm{O}$. atter warming to $170^{\circ} \mathrm{K}$. Due to the wide linewidths the $\beta$-deuteron $5 p \mathrm{itt}$ ing is not resolved. To eliminate the possibility that a binolecular reaction of the radical with the parent compound was occuring, experiments were performed where the original concentration of ExMeU was var ied over 10 told In $\mathrm{LiCl} / \mathrm{H}_{2} \mathrm{O}$. The results showed no change in the rate of production of the third radical species with cohcentration as would be expected for a hydration reaction.

5-Bromo-6-Methyluracil in an Alkaline Glass: Electron attachment to BrMeV in $B M$ NOOD at $77^{\circ} \mathrm{K}$ resulted in an esr spectrum consisting of a 86 
wide singlet at $g=2,0022$. Since a quartet spectrum is expected for the $\pi$-anion, 15 the results suggest the $\not$-anion radical is not stable in $8 \mathrm{M}$ NaO0 The observed spectrum is associated with the 6-methyluracil-5-yi radical (radical TV).

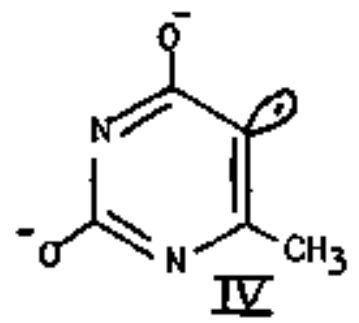

Although radical II shows no more resolution than the very similar radical $I$, the linewidth for radical IV is considerably less than that found for II. This may be due to the structural differences in the two radicals. harming radical $\mathrm{IV}$ to $160^{\circ} \mathrm{K}$ resulted is a second radical perhaps due to a hydration reactlon. However this spectrum has not yet yielded to interprefation.

The greater stability of the anion in the neutral glass over that found In the alkaline glass may be due in part to the fact that the nitrogens are protonated in the neutral glass. In addition the production of a neutrat radical by protonation of an axygen is also likely. This would further stabilize the radical. Such oxygen protonsted radicals hove been suggested from studies of the $\boldsymbol{\gamma}$-irradiation of 5 -halouracil single crystals, and the pulse radiolysts of thymine in aqueous solution. 16

\section{5-Halouracils in a Neutral Glass}

5-Bromouracil: Electron attachment to 5-bromourac if (BrU) at $77^{\circ} \mathrm{K}$ in $12 \mathrm{M} \mathrm{LiCl} / \mathrm{D}_{2} \mathrm{O}$ or $/ \mathrm{H}_{2} \mathrm{O}$ results in a $13 \mathrm{G}$ doublet spectrum ot $9=2.0025$ as shown in Figure $2 \mathrm{~A}$. Harming to $155^{\circ} \mathrm{K}$ results in a irreversible conversion to a broad 316 singlet in $\mathrm{D}_{2} \mathrm{O}$ (Figure 2B). In $\mathrm{H}_{2} \mathrm{O}$ the singlet is somewhat more broad. In I ight of the results found for MeBrU, where the well resolved anton converts to a broad singlet, a reasonable explanation of these results 
Is that the initial spectrum is due to the anion or protonated anion and the second broadened spectrum is cue to the uracil-5-yl radical (W). We therefore tentatively assign the intial species to the anion radical and the second specles to the uracilyl radical. Upon warming the second species to $160^{\circ} \mathrm{K}$ in $\mathrm{LiCl} / \mathrm{H}_{2} \mathrm{O}$ a quartet spectrum shown in $\mathrm{F}$ igure $2 \mathrm{C}$ is found. interpretation of this spectrum results in a $42 \mathrm{G}$ ( $\beta$-proton) splitting and a $20.56\left(\alpha\right.$-proton) coupling. In $\mathrm{D}_{2} \mathrm{O}$ only a 196 doublet is observed. These results are excellent evidence for the hydration of the uracityl radical to produce radical 표 as in reaction 3.
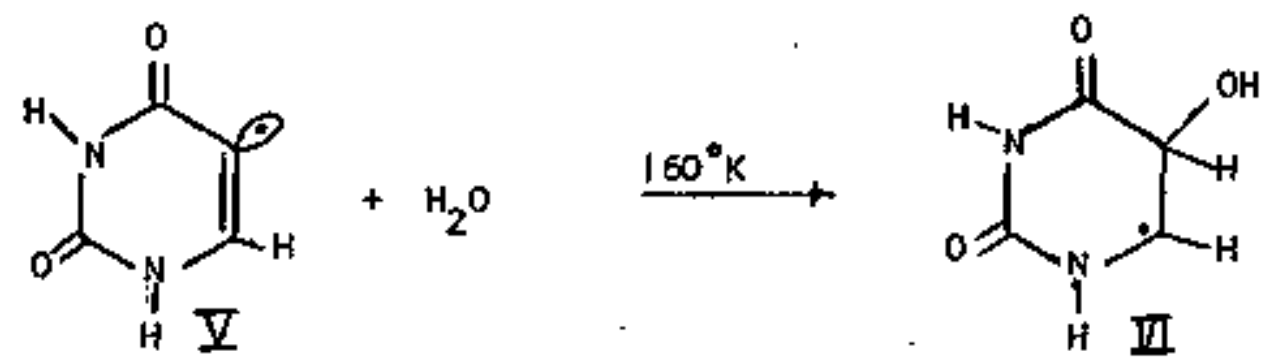

It samples are warmad directly to $165^{\circ} \mathrm{K}$ where the glass sottens to allow radjcal migrafion the quartet spectrum appears in much Jessoned intensity. This is attributed to radical-radical recombination which competes with the hydration reaction at these temperatures.

5-Chlorouracil: Electron attachment to 5-chlorouracil (CIU) in 12M $\mathrm{LiCl} / \mathrm{O}_{2} \mathrm{O}$ or $/ \mathrm{H}_{2} \mathrm{O}$ results in an esr spectrum consisting of a $15 \mathrm{G}$ doublet splitting at $g=2.0029$ (Figure 20 ). The radical remained stable to $165^{\circ} \mathrm{K}$ where the glass sottens. The $g$ value, hypertine splitting and temperature stability of this radical strongly suggest that it is the anion or protonated anton. No evidence is found for a broad singlet spectrum expected for a uracilyl radical; however, a partial conversion to a quartet identical to that found for $\mathrm{BU}$ is found to appear at $165^{\circ} \mathrm{K}$ in some experiments. This may be due to partial dehalogenation of the anion caused by the warming or more I ikely by light during photobleaching and transfer. 
5-fluorouracil: Electron attachment to 5-fluorouracil (FU) at $77^{\circ} \mathrm{K}$ results in evidence for an exceptionally stable anion. Over the temperature range $77^{\circ} \mathrm{K}$ to $170^{\circ} \mathrm{K}$ a spectrum is found consisting of a $13 \mathrm{G}$ doublet further split by a second doublet of 5.36 with $g=2.0033$ (Figure 2E). This second splitting is likety ofue to interaction with the ffuorine atom in the anion. This is reasonable in light of the nuclear spin of $1 / 2$ for tluorine and the fact that even a smalt spin density on a fluorine can result in a relatively large hyperfine splitting. 17 No temperature dependence in hyperfine splitting or $g$ value was observed.

3. 5rHalouractIs in an.Alkal ine Glass:

Reaction of electrons with the 5-halouracils in 8 M NoD resulted in stable $\pi$-anions in two cases. Electron attachment to FU at $77^{\circ} \mathrm{K}$ resulted in an esr spectrum whose analys is yielded a $12 \mathrm{G}$ splititing at $\mathrm{g}=2.0033$. The $g$ value is the same as found in $L i C l$ and is good evidence for a $x$-anion radical. No further reaction was noted upon photobleaching with unfiltered fight or warming. At $77^{\circ} \mathrm{K}$ electron attachment to clu resulted in an inttial spectrum indicative of the $\pi$-anion. The spectrum consists of a 146 doublet at $9=2.0028$ (Figure $3 A$ ). The $\mathbb{Z}$-anlon was Jight sensitive and upon irradiation with unfiltered I ight from an incandescent lamp for 10 minutes converted to a much more well resolved $13.1 \mathrm{G}$ doublet $\mathrm{splitting}$ at $g=2.0022$ (Figure 38 ). Irradiation for Intermediate time periods resulted in spectra which showed an overlap of both the $\mathrm{z}$-anion and the second radical, Electron attachment to $\mathrm{BrU}$ at $77^{\circ} \mathrm{K}$ resulted in a spectrum identical in hyperfine splitting, 9 value and I ineshape to the second radical found for clu. In addition both the second radical from CIU and the ErU radical power saturated readily; thus, low microwave power levels were utiljzed in the recording of their spectra. These spectra are likely due to the uracil-5-yl radical (radical vil) produced 
by dehalogenation of the $\pi$-anions of ClU and Bru. Several tindings support this conclusion. The low $g$ value is indicative of a signa radical. ${ }^{18}$ The 13 splitting observed for this radical is in the range expected for sigma radicals of aromatic systems. For example the phenyl radical has an orfto splitting of 186 whereas the 2-pyridyl radical has an ortho hydrogen splitting of $8 \mathrm{G} .^{19}$ The fact that Bru and Clu give identical spectro is also good evidence for dehalogenation. Finally the improved resolution of the uracilyl radical in $\mathrm{NaOD}$ over that found in $\mathrm{LiCl} / \mathrm{O}_{2} \mathrm{O}$ is in agreement with the results found for 6-methyluracil-5-yl in the two media.<smiles></smiles>

In I ight of these results we must correct our previous work where we reported stable anions for all holouracils in $8 M \mathrm{NaOO}$ at $-160^{\circ} \mathrm{C}$. In our present work we have shown that the BrU $\pi$-anion is unstable in $8 M$ NaOD even at $77^{\circ} \mathrm{K}$; whereas, the $\mathrm{FU}$ and $\mathrm{ClU} \pi$-anions are found to be stable at $77^{\circ} \mathrm{K}$. Since in the previous work samples were photobleached with unfiltered light the ciu y-anton was likely predominantly converted to the uracilyl radical. The report by Simpson and Zimbrick that all halouracil anions are unstable taward dehalogenation at $77^{\circ} \mathrm{K}$ in $\mathrm{BM} \mathrm{NaOD}$ is also in disagreement with the results of this work. These warkers do not report photobleaching with filtered Iight. This would explain the lack of observance of the clu anion. Since the BrU romion is unstable it would at so not be observed; however, the fut $\pi$-anion is stable to visible light and should be observed. An explanation for the difficulty in the indentification of the radicals observed in $B M \mathrm{NaOO}$ in our work and other work is that the halouracil $\pi$ anions and the uracilyt radical have very similar spectra in the alkaline glass. 
However as we have indicated these radicals can be distinguished by dtfferences in $g$ value, Ineshape and power sotusation behavior.

\section{Compar ison to Qther work and Conclusions}

A comporison of our results with some recent work is of interest. Eansal, Patterson and Schuler in work emploving conductometric pulse radiolysis report that $15 \%, 50 \%$ and $80 \%$ of the hydrated efectrons in aqueous solution react to form $\mathrm{F}^{-}, \mathrm{CJ}^{-}$and $\mathrm{Br}^{-}$from the respective halouracii." The yields of haltide ion found are not directly comparable to our results; however, they are reasonable in light of the relative stabilities of the antons tound in our work. Patterson and Bansal turther report in a separate pulse radiolysis study that the stabilities of the halouracil andons are in the order: FU> CIU\》Bru. We find the same order of stabilities in the neutral and alkal ine glasses. We also find that the anions of the halouracils are more stable in the neutral glass than in the alkaline glass. This is likely due to protonation of the anion at one of the oxygens to produce a neutral radical as was suggested to explain the similar results found for the BrMeU anion in the two media. Patterson and Bansal also report that the uracilyl rodical gave a hydrolysis intermediate. This finding is in good agreement with the results found here. However, we have been able to identify the hydrolysis intermediate as radical VI.

Zimbrick, Mard and Myers have hvpothesized a mechanism for radiation sensttization of BrU-ONA. They suggest that electron attachment to BrU in Bru-DNA results in the uracilyl radical and that this species subsequently abstracts from an adjacent deoxyribose group. The tinal step leads to single strand breakage. This mechanism is quite plausible. However, we can suggest 
that the hydration of the uracityl radical is a possible competing reaction with the abstraction reaction. This is ressonable is light of the fact that the uracilyl radical would have restricted movenent in the ONA structure. The hydrated radical it formed could of course also abstract from the ribose group; although, this would be less favored energetically than abstraction by the uracilyl radical.

\section{Acknowledoment}

The authors would I ike to thank Virginia Brooks for synthesis of 5-bromo-6-methyluracil. 


\section{References and Footnotes}

1. This research was supported in part by the Division of Biomedical and Environmental Researeh of the U.S. Atomic Energy Commission.

2. J. E. Zimorick, J. F, Ward and L. S. Myers, Jr., Int, J, Radiat, Biol, 16. 505 (1969); ibjd, 16, 525 (1969).

3. K. M. Bansal, L. K. Patterson and R. H. Schuter, 1. Phys Chem, 76, $2386(1972)$,

4. L. K. Pattersón and K. M. Bansal, jbid, 76, 2392 (1972).

5. P. Neta, ibid, 75, 2399 (1972).

6. J. Hơttermann and A. Míl ler, Int._J. Radiat, Biol. I5, 297 (1969).

7. E, G. Nice and D. Aorke, ibid, 15, 197 (1969).

8. M. D. Sevilla and C. Van Paemel, Photochem, Photobiol, 15, 407 (1972).

9. L. D. Simpson and J. D. Zimbrick, Radiat. Res, 51, 459 (1972).

10. T. Sasaki and M. Ando, 迎1, Chem, Soc. Jag., 4J, 2215 (1968).

11. M. D. Sevilta, J. Phys, Chem, 74, 669 (1970).

12. H. D. Sevilla, C. Van Paemel and 6. Zorman, ibid, 76, 3577 (1972).

13. J. Baudet, 6. Berthier and B. Puliman, Compt. Rend, 254, 762 (1962).

14. M. D. Sevilla, derys, Chem., 75, 626 (1971).

15. Due to the fact that the nitrogens of the parent coupound are deprofonated in this alkaline matrix, this species is likely a trianion radical. To emphasize the fact that it is the $\not /$-electron system which has gained the electron the radical is designated a $\pi$-anion radical.

16. L. M. Theard, F. C. Peterson and L. \$. Myers, Jr., d. Amer. Chem. Soc., $75,3815(197)$.

17. A. Carrington and A. O. Mclachlan, "Introduction to Magnetic Resonance" Harper and Row, New York, 1967, p. I12.

18. R. W. Fessenden and R. H. Schuler, J.Chem, Phys, 39, 2147 (1963).

19. J. E. Bennett and B. Mile, J.Phus. Chem., 75, 3432 (1971). 


\section{Figure Legends}

Figure I Esr spectra of radicals formed by electron attachment to 5-bromo-6-methyluracil in $12 M \mathrm{LiCl}$. A, The andon radical(I) or its protonated analogue in $\mathrm{D}_{2} \mathrm{O}$ at $77^{\circ} \mathrm{K}$. B. The 6-methyluraciJ-5-yl radical (II) In $\mathrm{D}_{2}$ o after warming to $150^{\circ} \mathrm{K}$, C. The 5-hydroxy-6-methyl-\{5,6)-dihydrouracil-6-yl radical (ID) after further warming to $165^{\circ} \mathrm{K}$ in $\mathrm{H}_{2} \mathrm{O}$.

Figure 2 Esr spectra of radicals formed by electron attachment to 5-halouracils in $12 \mathrm{M} \mathrm{LiCl}$. A. The 5-bromouracil anion or its protonated analogue at $77^{\circ} \mathrm{K}$ in $\mathrm{D}_{2} \mathrm{O}$. B. The uracll-5-yl radical ( $\mathbb{E}$ produced by warming the bromouracll anion to $155^{\circ} \mathrm{K}$ in $\mathrm{D}_{2} \mathrm{O}$. C. The 5-hydroxy-(5,6)-dihydrouracit-6-yl radical (स्E) produced by warming $\bar{Y}$ to $160^{\circ} \mathrm{K}$. 0 . The chlorouracil anjon or protonated analogue at $77^{\circ} \mathrm{K}$ in $\mathrm{D}_{2} \mathrm{O}$. E. The fluorouracil anion or protonated analogue at $140^{\circ} \mathrm{K}$ in $\mathrm{D}_{2} \mathrm{O}$.

Figure 3 Esr spectra of radicals formed by electron attachment to 5-chlorouracil in $8 M$ NBOD. A. The 8 -anion radical at $77^{\circ} \mathrm{K}$. B. The urac $\left\{1-5-y \mid\right.$ radicat at $110^{\circ} \mathrm{K}$ formed by photolyzing the radical in $A$ with unfiltered visible light. 


$$
\text { 许 }
$$




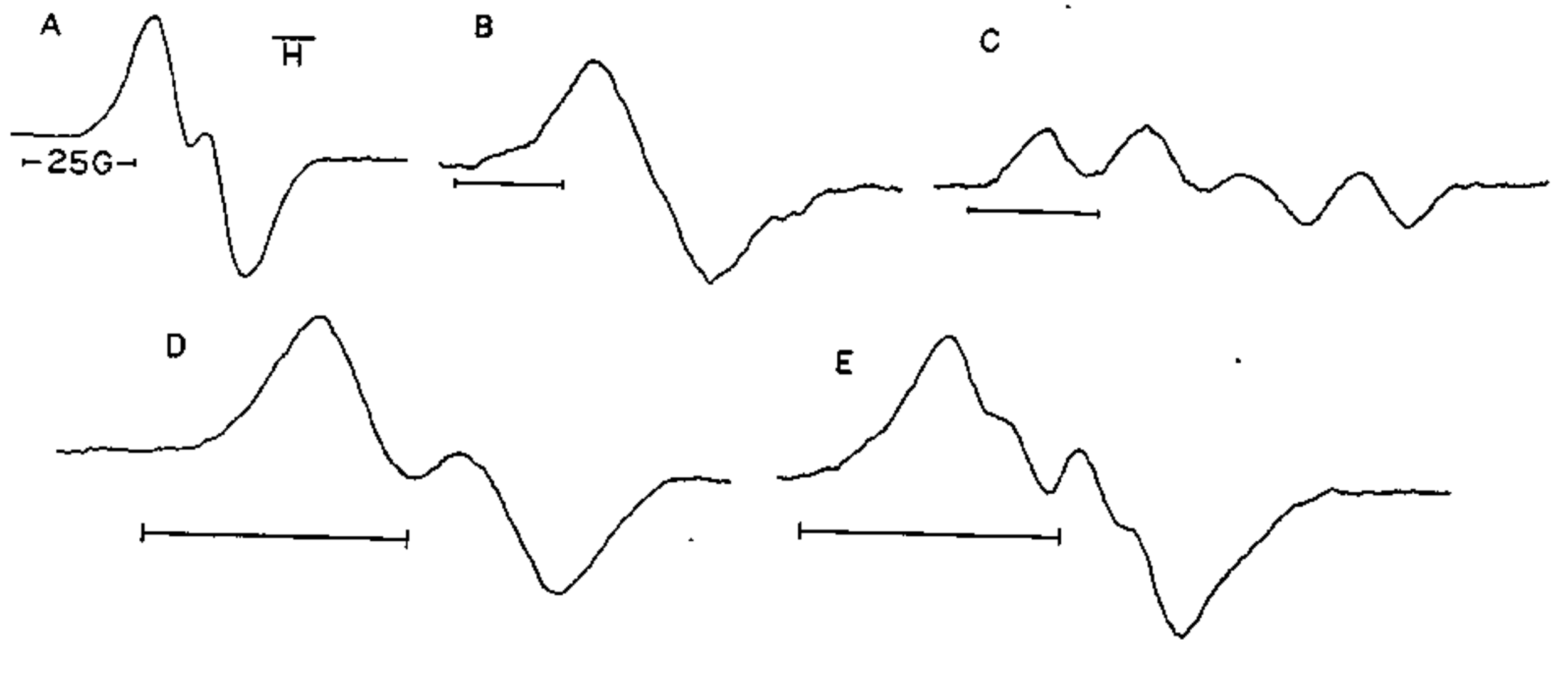




$$
\text { in }
$$


The Purine DNA Base Cation and Anion Radicals: An ESR Study

by M. D. Sevilla and P. Mohan Department of Chemistry Oakland University

Rochester, Mfchtgan

Ruming Titele: Purtne Ion Radfcals 


\section{Introduction}

The radical ions of the DNA bases have recently been reported as the primary incermediates in the radiolysis of DNA. Graslund et a1, report that the anionic radical in $\gamma$-irradiated DNA is likely that of thymine (or cytosine) and the cationic rodical is that of quanine (or cytosine). For these results it is clear that investigations of the ion radicals of the Indfvidual DNA bases are of Importance to the understanding of the effect of radiation on DNA.

The cation and anion radicals of the pyrimidines, thymine and cytosine, have been investigated and their further reactions elucidated in a number of ESR studies employing aqueous glasses (Holroyd and Glass 1968, Srinivasan, Singh and Gopal-Agengar 1969, Lion and van De Vorst 1971, Sevilla and Van Paemel 1971, Sevilla, Van Paemel and Nichols 1972, Sevilia, Van Paeme 1

and zorman 1972). The ion radicals of the purines have not been ss thoroughly investigated partially due to the poor resolution found for their ESR spectra. However Lion and van De Vorst report studies cf the anion radice1s in alka1ine aqueous glasses at tow temperatures. The antons are reported to undergo protonation reactions upon UV irradiation. Both the anions and cations of the purines, adenine and quenine, have been reported in ESR studies of $Y$-ircadiated polycrystaline purines (Dertinger and Hextig 1972). Onty the $g$ values are reported by Dertinger and Hartig due to poor resolution of the ESR spectra.

In this work we have investigated the cation and anton rodicals of the purine DNA bases in nettral aqueous glasses. The purpose of this investigation was ta determine the g values of the purine ion radicals for compartison to those found in polycrystalline purines and to investigate. possible protonation reactions of the purine antons in a neutral aqueous medium.

\section{Matertals and Methods}

Several techniques were employed to generate ion radicals of adenine and quanine. The positive ions were produced by photoionization (254 nm) at $77^{\circ} \mathrm{K}$ of $10^{-3} \mathrm{M}$ purine in $12 \mathrm{M} \mathrm{LiCl}\left(98^{\circ} \mathrm{D}_{2} \mathrm{O}\right)$. The photoionization process has been previously described ond suggested to be a biphotonic process (Sevilig, Van Paemel and Nichols 1972, Helene, Santus and Douzou 1966). To produce the cati-ii whthout interference from the photoejected electron 
$\mathrm{K}_{3} \mathrm{Fc}(\mathrm{CN})_{6}\left(\leq 10^{-2} \mathrm{M}\right)$ was added as an electron scavenger. To produce the anions of the purines without interference from the cations $10^{-2} \mathrm{M} \mathrm{K} / 4 \mathrm{Fe}(\mathrm{CN})_{6}$ in $12 \mathrm{M} \operatorname{LiCl}\left(\mathrm{D}_{2} \mathrm{O}\right)$ was photoionized in the presence of $10^{-3} \mathrm{M}$ purine.

The purines were obtained from Schwriz. The g values were measured va. peroxylamine disulfonate, $g=2.0056$, utilizing a varian v-4500-10A ESR spectrometer.

\section{Results and Discussion}

The ESR spectra after photolysis of samples containing adenine or quanine in 12 i $\mathrm{LCl}\left(\mathrm{D}_{2} \mathrm{O}\right)$ consist of unresolved singlets which are considered to be the overlap of the spectra of the purine cation,trapped electron and a smalt amount of purine anion. Photoblcaching ( $\lambda \geq 4300 \AA$ ) mobilizes the electron and results in a combined ESR spectrum of the positive and negative ions. Some reduction in total intensity results in this step from the reaction of the electron and cation. The spectra at this point show no resolution and have linewldths in the range 11 to $13 \mathrm{~g}$ (Table 1). The $g$ values for the combined spectra of the purines (Table 1 ) are corsidered to spproximate the average of the cation and anion radicals. This-would only be exactly so if each radicals spectrum were of the same lineshape and innewidth.

Samples wifch contained $\mathrm{K}_{3} \mathrm{Fe}(\mathrm{CN})_{6}$ as an electron scavenger resulted after photoionization and photobleaching in ESR spectra which are considered to be due to cations. These spectra are also unresolved singlets. Their $g$ values and linewidths are greater in magnitude than found for the combined spectra (Table I).

The purine anion radicals were produced by the photoionizstion of $k_{4} \mathrm{Fe}(\mathrm{CN})_{6}$ technique. The ESR spectra of the adenine and quanine anions were virtually unresolved. The $g$ value reported in the table for the anions are less than those found for the cations. The overall resulcs are self consistent since the anion and cation $g$ values average to about the mixed anioncation values.

Lion and van De vorst report the $g$ values for the purine anion radicals In $2 \mathrm{M}$ NaOl at $77^{\circ} \mathrm{K}$ to be 2.0028 (adenine) and 2.0035 (quanine). The results for adenine differ somewhat from those found in I2M LiCl. This may be due to the alkaline medium which removes the 9 position nitrogen proton ( $\mathrm{pK}=9$, ); although large differences in $\mathrm{g}$ value with matrix are unusual. The $\mathrm{g}$ vajins reported by Dertinger and Hartig for the ion radicals 
in irradiated dry polycrystalline adenine and quanine arc: anions $\mathrm{g}=2.0032$ (adentne), $g=2.0043$ (quanine); cations $g=2.0040$ (alenine), $g=2.0055$ (quanine). The $g$ values for adenine are within experimental error of those found here. However the results for quanine differ significantly. Since $g$ values found for the quanine anion in this work and by $L i o n$ and van De Vorst are considerably lower than reported by Dertinger and Hartig it is possible that the radicals attributed by Dertinger and Hartig to the quanine anjon and cation radicals are due to other spectes. For example, that value attributed to the quanine anion is nearly ideptical to the cation 8 value found in this work. Only in Y-irradfated orlented DNA has a resolved spectrun attributed to the quanine cation been reported (Graslund et a1, 1971). Unfortunately no $g$ value was reported for this radical.

We have performed experiments attempting to induce protonation reactions at carbon sites in the purine anion radicals in $12 \mathrm{M} \mathrm{LiC1}\left(\mathrm{H}_{2} \mathrm{O}\right)$. The anfons were generated either by photoionization of the purine or $\mathrm{K}_{4} \mathrm{Fe}(\mathrm{CN})_{6}$ with subsequent photobleaching of the trapped electrons. The anion radicals were then warmed to $180^{\circ} \mathrm{K}$ for varying periods of time. No evidence for a protonation reaction was found. A very small concentration of secondary radical was noted; however this was due to the reaction of hydrogen atoms with purine after warming. (A small concentration of hydrogen atoms is found at $77^{\circ} \mathrm{K}$. The hydrogen atoms are likely produced by electron reaction with $\mathrm{R}_{3} \mathrm{O}^{+}$). Liton and van $\mathrm{De}$ torst (1971) have noted that protonation reactions can be inđuced in purine anions in $8 \mathrm{M} N$ aOH glasses by UV Iight $(>3200 \dot{A})$. We have found the same result for quanine anion in $12 \mathrm{M} \mathrm{Licl}$. Lion and van De Vorst found in earlier work (1970) utilizing the ferrocycnide giethod for generating anions in an alkaline aqueous glass that no protonation occurred on warming. However in their more recent work (1971) in which $\gamma$-irradiation was employed they suggest protonation occurs on warming. In view of our results which show no protonation and their earlier results we would suggest that the radicals produced by warming $\psi$-irradiated aqueous glasses axe a result of attack by hydrogen atoms and hydroxyl radicals which are produced dtaring $\gamma$-irradiation and mobilized upon warming.

The results of this present work and previous work in both alkaline (llolroyd and Glass 2968, Srinivasan et a1, 1969, Lion and van De Vorst 1970) and neutral (Sevilla, Van Paemel and zorman 1972) glasses liave shown that 
. .

$\cdot+$

of the four DNA bases only the thymine anion readily protonates. We believe these results give the probable explanation for the fact that only the thymine anjon has been found to protonate in $\gamma$-irradiated DNA (Omerod 1965), 


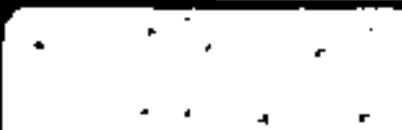

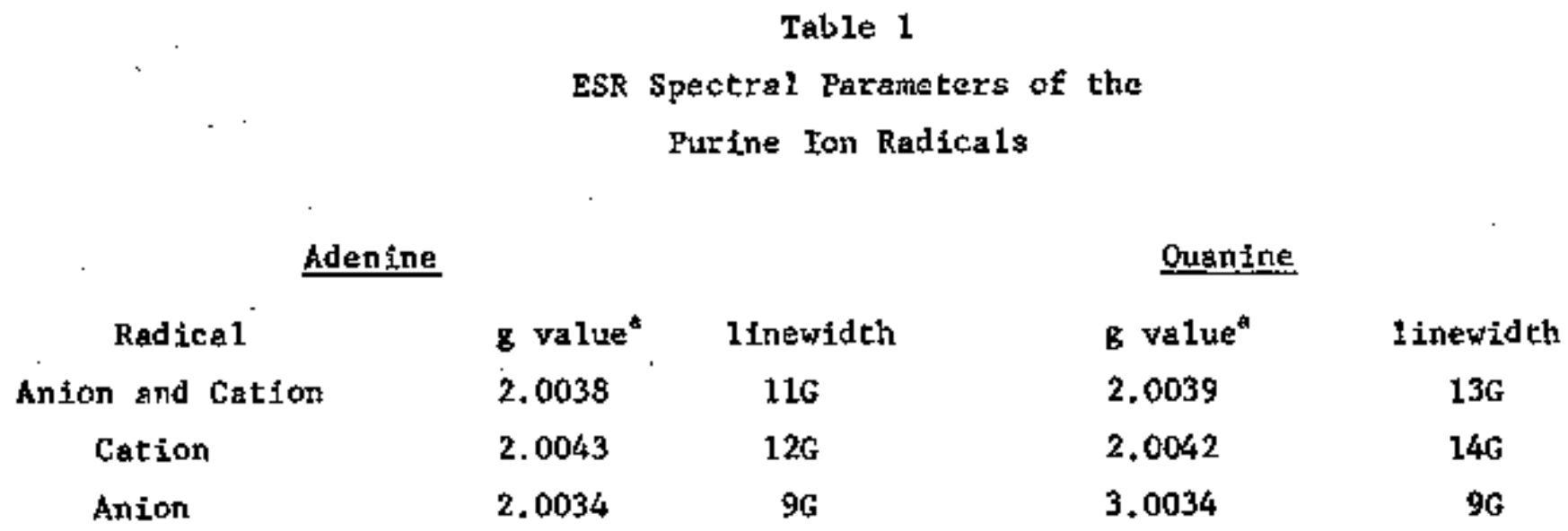

a. The uncertsinty on the g value is estimated to be \pm 0.0003 . 


\section{References}

Dettinger, H. and lartig G., 1972, Intern. J. Radiation Biol., 21, 279. Graslund, A., Ehrenberg A., Rupprecht A., and Strom, G., 1971, Biochem. Biophys. Acta 254, 172 .

Helene, C., Santus, R., and Douzou, P., 1966, Photochem. Photobiol., 5, 127.

Holroyd, R. A. and Glass, J., 1968, Intern. J. Radiation B101., 14, 445.

Lion, Y, and van De Vorst, A, 1971, Intern. J. Radiation Phys. Chem., 513 and 521 .

Lion, Y, and van De Vorst, A., 1970, Intern. J. Radiation Phys. Chem., $\underline{2}, 51$.

Ormerod, M. G., 1965, Intern. I. Radiation Biol, 9, 291.

Sevilla, M. D., Yan Paeme1, C., 1972, Photochem. Photobiol., 15, 407.

Sevilla, M. D., Van Paeme1, C., and Nichols, C., 1972, J. Phys. Chem+ $\underline{76}, 3571$.

Sevilla, M. D., Van Paemel, C., and Zorman, G., 1972, I. Phys. Chent. 16, 3577 .

Srintvasan, V. T., Singh B. B., and Gopal-Ayengar, A, R., 1969, Intern.

J. Radiation Biol., 15, 89 . 